\title{
FORMAÇÃO DOCENTE E ENSINO NAS DIVERSAS ÁREAS DO CONHECIMENTO
}

A Revista Contexto \& Educação - número 115, volume 36 - completa 35 anos (1986-2021) de publicação contínua ao tratar da formação docente e do ensino nas diversas áreas do conhecimento, num total de 24 artigos: 5 deles compõem a seção Interculturalidade e Educação, 3 a seção Educação, ambiente $e$ saúde, e os outros 15 a demanda espontânea.

Neste período, diversas compreensões e pesquisas em educação foram colocadas à disposição de estudiosos da área no que se refere à Educação Popular, ao Desenvolvimento de Currículo, à Formação Docente, à Interculturalidade, à Saúde, ao Meio Ambiente, ao Pensamento Computacional, dentre outros tantos temas. A cada exemplar publicado várias questões e reflexões foram provocadas pela continuidade das análises propiciadas, que motivam outras reflexões e observações bem delineadas, num diálogo singular com diversos autores.

Na seção Interculturalidade e Educação agrupamos cinco artigos que abordam a questão das cotas na universidade, da presença do negro nos livros didáticos, da religião, do gênero e da sexualidade. A seguir apresentamos os artigos.

O artigo de Gretha Leite Maia, intitulado Os desafios de implementação de cotas para pretos, pardos e indígenas (PPI) nas universidades brasileiras, constitui um estudo analítico da Lei de Cotas no Brasil na ocupação de vagas em reserva para estudantes Pretos, Pardos e Indígenas (os cotistas PPI). Analisa casos e conclui que a autodeclaração pode ser contrastada por comissões de heteroidentificação e contribuir para a efetividade da política afirmativa.

No segundo artigo, A representatividade da população negra em uma coleção de livros didáticos de geografia - PNLD 2018, Ana Carolina dos Santos Marques e Ricardo Lopes Fonseca discutem a perversidade do racismo, que, no Brasil, foca na população negra. A educação é um instrumento de sensibilização, conscientização, valorização, reivindicação e inclusão social dos negros que pode inibir com o racismo. Neste sentido, ao discutir o papel da educação na questão racial, este artigo investigou a representatividade dos negros na coleção de livros didáticos Ser Protagonista - Geografia - Ensino Médio, aprovada no PNLD 2018.

No terceiro artigo, Reflexões sobre a trama geográfica entre espaço e religião, Roseane Richele de Medeiros e Diego Salomão Candido de Oliveira Salvador apresentam reflexões sobre as tentativas de renovação da Geografia para compreender as relações entre ser humano e o meio e a religião.

No quarto artigo, intitulado Gênero e sexualidades em foco: discussões dos discentes do curso de especialização em ensino de biologia, modalidade a distância, em sua prática docente, Adelaine Ellis Carbonar dos Santos e Virginia lara de Andrade Maistro objetivam compreender como discentes do curso de especialização em Ensino de Biologia, modalidade a distância, discutem a temática de gênero e sexualidades em sua prática docente. Para tanto, foi aplicado um questionário via Google Docs a discentes 
matriculados em 8 polos, no período de 18 a 25 de maio de 2019. Partimos da premissa de que a escola se constitui heteronormativa e LGBTfóbica, em que o discurso biológico se configura como um regulador de práticas humanas.

Por fim, Andreia Freitas Zompero, Virginia lara Andrade Maistro e Maria Conceição Costa Matos, no artigo intitulado $A$ visão dos pais sobre a atuação da escola em assuntos relativos à sexualidade, objetivam identificar a visão dos pais dos alunos do sexto ano de um Colégio Estadual de um município brasileiro referente às intervenções da escola relacionadas às manifestações da sexualidade por parte dos alunos. Os participantes apresentam receios e divergências sobre a abordagem em cada caso, o que pode ser decorrente da falta de informação sobre diálogos em torno da sexualidade.

Na seção Educação, ambiente e saúde foram publicados dois artigos sobre educação e saúde e um sobre ambiente e sustentabilidade.

No artigo Educação Alimentar e Nutricional: análise de ações com adultos a partir do Marco de Referência, Lisiane Giusti, Ana Luiza Sander Scarparo e Eliziane Nicolodi Francescato Ruiz revisam e analisam produções brasileiras sobre o tema. Os critérios de elegibilidade dos textos foram: intervenções de educação alimentar e nutricional, público-alvo adultos e ações/intervenções realizadas entre o período de 2012 e 2018. Nenhum dos trabalhos analisados utilizou diretamente o Marco de EAN como referência na descrição metodológica ou como base teórica.

No artigo intitulado Estrutura de planejamentos de aula para o ensino fundamental: análise de propostas didáticas sobre o sistema circulatório, Thanara Muraro de Christo e Lenira Maria Nunes Sepel investigam a estrutura e recursos de planos de aula sobre sistema circulatório, disponíveis no Portal do Professor - Ministério da Educação. Foram coletados no Portal todos os planos de aula que citavam o sistema circulatório (141 planos), e selecionados apenas os que desenvolviam o conteúdo (15 planos) para a análise da problematização, dos recursos didáticos e avaliação, fundamentados nos Três Momentos Pedagógicos e no Modelo Instrucional BSCS 5E.

No artigo Reflexão e diálogo sobre sustentabilidade no Ensino Básico e Superior, Norma Barbado e Ana Carolina Barbosa de Souza objetivam promover o diálogo e a reflexão sobre sustentabilidade a partir de conhecimentos prévios dos estudantes da Educação Básica e do Ensino Superior no Instituto Federal do Paraná - Campus Umuarama. É uma pesquisa-ação que iniciou com um diagnóstico composto por 8 questões, aplicado a 36 discentes, formando 3 grupos focais: 1) 10 estudantes do Ensino Médio (educação básica); 2) 21 estudantes de Graduação (Ensino Superior); e 3 ) 5 estudantes do Mestrado em Sustentabilidade (Ensino Superior Stricto Sensu).

Os 16 artigos da demanda espontânea tratam de aspectos relevantes da formação de professores da universidade e da educação básica, além de abordar aspectos do desenvolvimento do currículo em relação ao ensino.

No artigo Educação popular e educadores sociais nas universidades: a luta dos movimentos sociais, Fernanda dos Santos Paulo e Elenita Lopes da Silva discutem a relação trabalho-formação de educadores sociais atuantes nas periferias de Porto Alegre-RS. Apresentam as categorias educador popular, educador social e espaços educativos 
de Educação Não Escolar. As categorias foram contextualizadas histórico-politicamente e conectadas aos movimentos sociais na perspectiva da Educação Popular articulada ao Serviço Social.

No artigo Representações conceituais de docentes do Mercosul acerca da transversalidade, Cátia Silene Carrazoni Lopes Viçosa, Vanderlei Folmer e Andréia Caroline Fernandes Salgueiro investigam as concepções de docentes brasileiros, argentinos e uruguaios acerca da transversalidade na educação básica. A Análise de Conteúdo permitiu identificar quatro categorias: i) contextualização; ii) aprendizagem significativa; iii) formação de sujeitos; e iv) interdisciplinaridade. Os temas com maior frequência são semelhantes nos países pesquisados e estão relacionados ao Meio Ambiente e à Saúde, mas o Uruguai destaca-se, em relação à Argentina e ao Brasil, na formação continuada focada na transversalidade.

O artigo intitulado Isolamento social: percepções discentes sobre o deslocamento das interações acadêmicas para meios digitais, de Rafael Winícius da Silva Bueno, Thelma Duarte Brandolt Borges e Valderez Marina do Rosario Lima, foi realizado durante o contexto de isolamento social de 2020, demandado pela pandemia da Covid 19. Os autores analisam as percepções de estudantes de Graduação que tiveram suas atividades deslocadas da modalidade presencial para a remota. As informações foram analisadas, por meio da Análise Textual Discursiva, em um movimento de desconstrução e reconstrução de ideias. Emergiram as categorias das percepções discentes: Compreensão e Enfrentamento das Dificuldades e Necessidade de Interação Dialógica Presencial, discutidas nos metatextos.

Gustavo Lopes Ferreira e Maria Luiza de Araújo Gastal, no artigo A inserção e as contribuições dos Institutos Federais à formação de professores, questionam os motivos da atribuição aos IFs da função de formar professores, as prerrogativas legais dos Ifs, em quais regiões do Brasil formam professores, entre outros aspectos. Utilizaram como fonte documental pesquisas sobre o tema dos IFs e da formação de professores, a Lei $n$ 으 11.892/2008, bem como dados da Plataforma Nilo Peçanha.

No artigo $O$ papel do estágio curricular para a formação docente: visão dos educandos do curso de Licenciatura em educação do campo, Helena Maria Beling, Janete Webler Cancelier e Carmen Rejane Flores refletem sobre a importância da realização do estágio curricular supervisionado II para discentes do curso de Educação do Campo, ofertado na modalidade a distância pela Universidade Federal de Santa Maria (UFSM), a partir de experiências vivenciadas pelos estagiários nas escolas. A pesquisa foi desenvolvida com alunos matriculados na disciplina de estágio da primeira oferta do curso, que abrange os polos de apoio presencial de Agudo, Cerro Largo, Itaqui, Seberi e São Sepé. As atividades do estágio possibilitam interação com diversas realidades escolares, momento no qual os estudantes são flexionados a realizar a intermediação entre os conhecimentos teóricos e práticos, buscando, a partir desta vivência, internalizar práticas que os constituem enquanto docentes. Destacamos a importância dos estágios para os futuros docentes no sentido da consolidação de práticas emancipatórias.

No artigo $A$ formação docente em química e as práticas pedagógicas dos professores da educação básica, Christian Dias Azambuja, Mara Elisângela Jappe Goi e Ângela Maria Hartmann relatam uma pesquisa sobre formação docente para compreender 
como os professores de Química avaliam o desenvolvimento de práticas docentes em sala de aula. A investigação buscou compreender a influência da formação específica e pedagógica sobre o trabalho docente de professores de Química. A partir dos dados, foi possível identificar as concepções sobre ensino e aprendizagem dos professores e compreender como sua formação acadêmica contribui para a prática pedagógica.

No artigo As intervenções do PIM como objeto de análise, Fernanda Dias Almeida, Fernanda Antoniolo Hammes de Carvalho e Edison Luis Devos Barlem, refletem sobre programas que estimulem atividades relacionadas ao desenvolvimento integral das crianças na primeira infância. Os autores analisam o Programa Primeira Infância Melhor (PIM), criado pelo governo do Estado do Rio Grande do Sul e coordenado pela Secretaria da Saúde do Estado com apoio das Secretarias de Cultura, Educação, Trabalho e Desenvolvimento Social, uma política de governo que atende famílias vulneráveis com gestantes e crianças de zero a 3três anos, encaminhadas, em especial, pela UBSF.

Nathany Morais de Souza, Micarla Silva de Azevedo e Denise Cortez da Silva Accioly, no artigo Sentimentos e emoções no contexto da educação infantil: um caminho que leva à empatia e à compreensão do próprio eu, analisam uma experiência de estágio na regência referente ao componente curricular Estágio II (Educação Infantil) do curso de Pedagogia da UFRN/Ceres/Caicó. Focaram na temática "sentimentos e emoções" no contexto da Educação Infantil e sua influência nas relações interpessoais e no processo de ensino-aprendizagem.

No artigo As tendências curriculares na década 1970 e o caso do Projeto Logos II, Cristiane Talita Gromann de Gouveia e Sérgio Candido de Gouveia Neto elaboram uma história do currículo na década de 1970 partindo da análise do currículo do projeto Logos II. Além disso, evidenciam os conceitos da educação tecnicista que estruturaram o currículo brasileiro, e, consequentemente, a estrutura curricular do Projeto Logos II.

Beatriz Marques Assad, Rebekah Giese de Paula Machado e Evander Ruthieri Saturno da Silva, no artigo A evolução biológica à luz da cultura científica e história da ciência em livros didáticos do Ensino Médio (PNLD, 2015), analisam o conteúdo de evolução biológica quanto aos elementos caracterizados como História da Ciência e de cultura científica em três livros didáticos de Biologia. A ocorrência da cultura científica aconteceu majoritariamente nos conteúdos compreendidos em seções extras do livro.

No artigo Análise de imagens de textos de divulgação científica inseridos em livros didáticos de biologia, Pedro Henrique Ribeiro de Souza e Marcelo Borges Rocha analisam 31 imagens em 27 textos de DC relativos à biologia animal, presentes em sete LDs de Biologia para o Ensino Médio. De acordo com a classificação semiótica e conceitual, foi possível perceber que a maioria das imagens possui caráter naturalista, quando há proximidade com o real, e simbólico, conferindo atmosfera para os textos. Identificou-se maior interação ou contraste na relação entre as informações do texto e a imagem.

No artigo A mediação didática na aprendizagem: a construção do conhecimento geográfico, Izabella Peracini Bento buscou compreender o conceito de mediação na teoria histórico-cultural e destacar a importância da mediação didática para a aprendizagem geográfica. Este trabalho fundamentou-se na Teoria Histórico-Cultural e tem por objetivo utilizar como referência básica um de seus precursores: o professor e pesquisador bielo-russo Lev Semionovitch Vigotski (1896-1934). 
No artigo $O$ ensino de história e educação patrimonial na educação básica: desafios e possibilidades, Clara Zandomenico Malverdes e Maria Alayde Alcantara Salim apresentam uma pesquisa participante que contou com uma intervenção e aplicação de uma metodologia chamada "Imaginando", cujo princípio foi a utilização da linguagem fotográfica na representação do conceito de patrimônio. Investigam a ampliação do conceito de fontes na produção historiográfica brasileira e a relação entre o ensino de história e a educação patrimonial no âmbito dos anos iniciais, apresentando problemas e possíveis possibilidades de intervenções pedagógicas.

No artigo Compreensões de licenciandos sobre a superação das dificuldades de aprendizagem no Ensino Fundamental, José Moysés Alves relata uma pesquisa sobre a própria prática de três professores formadores em uma turma de 22 licenciandos, com o tema Compreensão e Explicação dos Processos de Desenvolvimento e Aprendizagem II. A superação das dificuldades de aprendizagem foi um dos assuntos estudados a partir da visão da teoria da subjetividade.

Symara Abrantes Albuquerque de Oliveira Cabral e Sayonara Abrantes de Oliveira Uchoa, no artigo Lugar do léxico no desenvolvimento do ensino e da capacidade leitora, discutem a importância de processos de ensino de leitura pautados nas relações lexicais como metodologia eficiente ao desenvolvimento da competência leitora. Os resultados apontam para a eficiência da construção de paradigmas de ensino de leitura, pautados no léxico, como contributos ao desenvolvimento de um leitor autônomo.

No artigo Uso de videoaulas como recurso didático: critérios de análise e seleção, Luciano Dias da Silva e Maurício Capobianco Lopes apresentam resultados de uma pesquisa cujo objetivo foi analisar o uso de videoaulas como recurso didático na sala de aula invertida em aulas de Físico-Química. Os instrumentos utilizados para a geração dos dados foram a internet (para a seleção das videoaulas), as anotações do professorpesquisador e um questionário de avaliação aplicado aos alunos. Como produto educacional foram gravados vídeos para compor uma playlist no YouTube, cujo objetivo é servir como guia para os professores que se interessarem pelo tema, além de playlists com as melhores videoaulas utilizadas durante a execução do projeto, cuja criação visa a facilitar a organização dos estudos de cada aluno e a pesquisa dos professores que não têm tempo de fazer sua própria seleção de videoaulas.

A diversidade de temas e análises apresentada nos textos disponibilizados confirma e permite comemorar os 35 anos desta Revista, caracterizada por apresentar questões que suscitam reflexões aprofundadas e ampliadas.

Convidamos os leitores para comemorar a longa vida deste periódico, que publica seu número 115.

Boa leitura

Maria Cristina Pansera-de-Araújo 